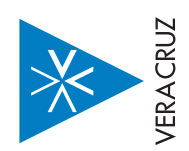

\title{
verals
}

ISSN 2236-5729

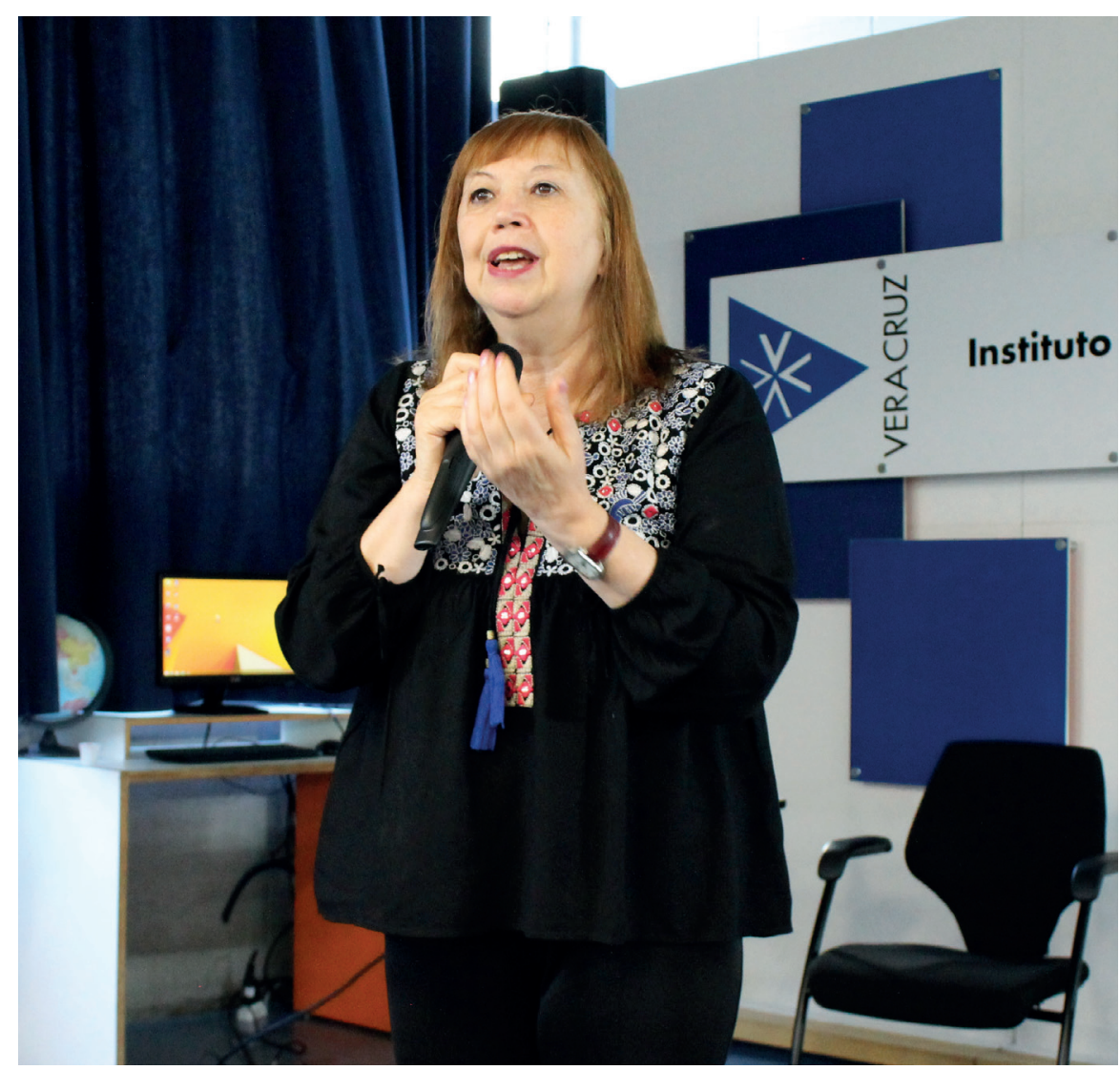

\section{Entrevista: Flora Perelman}

\section{"A chave são as palavras-chave"}

\section{Por Ricardo Prado}

A internet é um mar de letras e não devemos deixar os alunos sozinhos nessa imensidão. É preciso orientá-los, realizar visitas guiadas a sites, da mesma forma como as turmas fazem nos museus, e não deixá-los à deriva - até porque podem chegar a portos nada educativos. Esta é a opinião da pesquisadora Flora Perelman, Professora aposentada de Psicologia e Epistemologia Genética da Faculdade de Psicologia da Universidade de Buenos Aires, que fala nesta entrevista sobre seu principal tema de pesquisa: o impacto das tecnologias da informação e da comunicação na educação. 
Para Flora, "a busca pela palavra-chave cria um aprofundamento do conceito". Por isso que a chave está na construção das palavras-chave, e as discussões sobre os conceitos que se põem em jogo a partir dessa procura. "Esse é um processo construtivo muito interessante de se fazer com os alunos", recomenda a educadora, que também participou do desenho curricular da Educação Primária da Província de Buenos Aires na área de Práticas de Linguagem, além de ser autora do módulo "Ensinar leitura, escrita e oralidade com as TIC na Escola Primária" das orientações didáticas publicadas pelo Ministério de Educação da Argentina. Neste link da Universidade de Buenos Aires (https://uba.academia.edu/ FloraPerelman) é possível ler 39 artigos e duas conferências de Flora Perelman, que esteve no Brasil em abril de 2019, quando concedeu a seguinte entrevista à Revista Veras.

Revista Veras: A sra. pegou bem o início da internet nas escolas. 0 que suas primeiras pesquisas revelaram?

Flora Perelman: Em termos de pesquisa acadêmica me dediquei a investigar como os alunos buscavam informação na internet. Foi uma investigação feita em classe. Colocávamos um software nos computadores para estudar os caminhos que os alunos faziam até tomarem suas decisões. Gravávamos as discussões e também as intervenções dos professores. E o que nos chamou a atenção nessa pesquisa é que os professores não intervinham quase nunca, deixavam os alunos sós. E isso nos levou a pensar: "O que o professor precisa fazer?". Então, a partir dessa ideia, e do que víamos dos alunos, fizemos uma investigação didática.

Revista Veras: Em seu artigo "Ferramentas para ensinar a ler e produzir em meios digitais" a Sra. critica a pouca atenção que se dá ao trabalho de pesquisa na internet, que os professores sabem que seus alunos simplesmente se desobrigarão da função depois de visitarem um ou dois sites. Por que é tão importante uma estratégia didática como a visita guiada pelo professor a um site?

Flora Perelman: A visita guiada é uma construção didática, uma situação que criamos no âmbito de uma investigação. Nós observamos que quando os alunos têm a possibilidade de explorar o site, sempre acompanhados pelo professor, de conhecerem qual é 
a lógica daquele site, eles avançam na busca, e em seus saberes, e essas explorações lhes facilita a localizar as informações. 0 que nos interessa é que o meio digital ajude na construção do conhecimento porque ele não é algo independente. É preciso propiciar a construção do conhecimento. Então, quando um professor ajuda a entender os títulos, que sentido eles têm, a entender porque esse determinado vínculo, porque se amplia para este tema e não para outro, porque essas imagens têm relação com esse título... Ou seja, o aluno começa a construir sentido, mas acompanhado por um professor. Em um museu, por exemplo, é muito diferente se eu o percorro sozinha, olhando os quadros a partir do meu conhecimento, ou se faço uma visita guiada por um especialista. 0 mesmo quadro ganhará um sentido totalmente diferente porque há um especialista que me permite construir esse saber. Então, eu penso que [navegar pela internet] é como se fosse entrar em um museu.

Revista Veras: Tenho a impressão de que muitas vezes os professores tutelam demais seus alunos, cortando-Ihes a autonomia. Mas, no caso da internet, parece que esse movimento é justamente o contrário, tipo "se vira aí". Qual seria o motivo desse comportamento?

Flora Perelman: Porque houve uma representação social de que os alunos são nativos digitais, que sabem mais que o professor.

Revista Veras: Isso revelaria um receio dos professores de entrarem em uma área na qual podem saber menos que seus alunos?

Flora Perelman: Claro, os professores pensam que seus alunos, supostamente, dominam a máquina e sabem fazer muitas coisas. 0 professor poderia pensar, no entanto, que esta é uma representação social, não é a realidade; é uma ideia que tem circulado, há livros inteiros escritos dizendo que os alunos são nativos digitais, e, com isso, se chegou a esta ideia de deixá-los sós.

Revista Veras: Os textos nos principais sites consultados pelos estudantes, que costumam ser multimodais e interativos, supõem muitas vezes conhecimentos prévios, sendo classificados como "difíceis" pela Sra. neste mesmo artigo que citei. Como sair desse dilema: devemos simplificar a vida do estudante, buscar sites que falem a sua língua, ou faz parte da vida estudantil encarar os textos difíceis?

Flora Perelman: Primeiro de tudo: cada site é um problema que precisa ser explorado. Um site de internet não é igual a outro, não há uma 
estandardização na constituição e organização dos sites. Isso implica que, se eu conheço um determinado site, não quer dizer que saiba como funciona outro site. Por isso, para nós, a leitura exploratória é primordial, porque é necessário fazer uma navegação para se fazer um reconhecimento. Por outro lado, os sites são híbridos, possuem ligações que os fazem chegar a outros lugares, porque há hipertextos externos e internos, e quem vê uma home page não sabe a extensão daquele site, até onde chega. Quando eu pego um livro, sei que tem mil páginas, mas quando entro num site não sei sua extensão, sua complexidade, tampouco o conteúdo, porque é difícil encontrar ali um índice, já que não é um livro onde posso achar o que me serve. Alguns sites até têm uma espécie de sumário, alguns estão construídos de forma que se parecem com um livro, mas outros não. Então, este é um ambiente muito mais diverso.

Revista Veras: A Sra. aconselha os professores a trabalharem com dois conceitos para identificar sites bons para os alunos: confiabilidade e pertinência. Como se aprende a identificar esses conceitos com a turma?

Flora Perelman: Seria preciso, antes de tudo, esclarecer que há uma representação social também entre os professores de que estes devem ensinar técnicas de estudo. Eu sou contra isso. Por quê? 0 professor pensa que se ele ensinar o aluno a resumir, o aluno resumirá qualquer tipo de texto porque ele ensinou a técnica do resumo. Se eu ensino a técnica de buscar os sites que sejam pertinentes e confiáveis, pensa o professor, eu ensino uma vez e ele já saberá definitivamente porque eu ensinei a técnica. Mais ou menos como se ensinaria a usar um gravador... Mas não é uma técnica. É uma prática social de construção de conhecimento, de estudos. Qual é a diferença? Que vai depender do que eu vou estudar e do meu conhecimento sobre o tema. Como vou saber se tal site corresponde ao meu tema de estudo se nada sei sobre ele? A confiabilidade tem a ver com buscar pessoas e instituições que me darão garantias de que essa produção é confiável. Se eu conheço alguns historiadores que tenham estudado aquele tema, posso procurar sites que tenham um suporte científico que os sustentem. Mas se não conheço as instituições, nem conheço os pesquisadores, então começo a pensar num site que fale genericamente sobre o tema. Assim se forma um estudante, não é simplesmente se ensinar uma técnica

Revista Veras: Ou seja, esse é um processo que deve ser feito ao longo de todos os anos da escola? 
Flora Perelman: Sim, totalmente, não termina nunca. Quando os alunos entram na universidade isso eu descobri com meus alunos porque perguntava a eles quando faziam seus resumos, vi que geralmente fazem o resumo depois que o professor ensina a parte teórica. Eles têm que ouvir a aula e, depois, fazem o resumo, porque precisam entender onde esse professor irá focalizar e o que é importante para ele no desenvolvimento da matéria para depois buscarem isso nos textos. Há uma mediação do professor, que decide para onde quer ir. Decidir sobre a pertinência de um site também depende do que o professor deseja que se focalize sobre um determinado tema, que sempre carrega um monte de possibilidades. Por isso, o professor precisa orientá-los. Veja, que curioso, então: deixamos sós os alunos do Ensino Fundamental enquanto os alunos da Universidade têm um professor que os orienta em relação às pesquisas. E então, pergunto: como que no Fundamental se deixam os alunos sós e meus alunos da Universidade vêm escutar, tomam notas, e depois estudam? 0 que se passou aqui? Houve uma volta completa?! A ideia social de que o aluno é um nativo digital e está capacitado para tudo é falsa.

Revista Veras: Como essa navegação guiada aconteceria na prática em uma sala de aula?

Flora Perelman: Não se deve deixar o aluno sozinho diante de um "mar de letras", essa é a minha posição. Deve-se ajudá-lo, inicialmente, mostrando que neste determinado site ele encontrará o que está buscando. "Busque por aqui". Para um leitor pouco habituado o que ajuda muito é o recorte. Isso permite ao aluno se sentir menos perdido e encontrar: "aqui está o que eu procurava!" E se o aluno não encontra o que procura, o que se segue é recortar ainda mais; por exemplo, propondo: "Vou começar a ler e você me avisa quando encontrar o que estamos buscando." Eu me torno o leitor, se ele não pode ser. Quero dizer com isso que a ajuda é progressiva: quanto maior é o envolvimento do professor quanto menos o aluno se encontra capacitado para fazer essa busca.

Revista Veras: Ou seja, esse apoio do professor à navegação dos alunos vai depender também da avaliação que ele tem do grau de evolução de cada um na turma...

Flora Perelman: Sim, e essa é a chave. 0 pior que se pode fazer a um aluno é ouvi-lo dizer: "Isso não é pra mim, eu não consigo fazer" e não se fazer nada. Isto é o pior que pode acontecer. 
Revista Veras: 0 mecanismo de comparar coletivamente três sites em torno de uma mesma temática pode ser útil para esse letramento digital? Que tipo de resultados uma dinâmica como essa traz?

Flora Perelman: Começa a surgir a ideia de que não há verdade ou mentira, que há em cada site uma seleção e um modo de se apresentar aquela temática. Ou seja, que um mesmo tema pode ter diferentes pontos de vista e, também, diferentes modos de ser apresentado. E isso ajuda ao aluno a escolher também como representará o seu saber. Não é mostrar que um é melhor que outro, mas que são diferentes maneiras de se ver e apresentar um assunto. Peguemos, por exemplo, um tema que não seja polêmico, o corpo humano. Nele, o sistema digestivo. Um site apresentará de uma maneira, um segundo de forma diferente e um terceiro também. Há diferentes formas de se produzir conhecimento e isso também é uma aprendizagem: a de que, na construção do conhecimento, é possível apresentá-lo de muitas formas, com muitas linguagens.

Revista Veras: Por que é importante a troca de impressões entre os alunos e o professor em torno da leitura dos sites?

Flora Perelman: Porque é inimaginável o que podem pensar os alunos. Os adultos não podem imaginar! Eles têm caminhos cognitivos e interpretativos que nós não conhecemos. E que precisamos conhecer: "Quem é esse aluno que temos diante de nós? 0 que ele está pensando?" Piaget interrogava as crianças sobre tudo e descobria ideias absolutamente originais. Emilia Ferreiro o fez com a escrita, descobrindo hipóteses que nunca poderíamos imaginar. 0 que as crianças desenham, escrevem ou comentam em aula são hipóteses. E essas hipóteses não podem ser deixadas de lado. Além de muito ricas, é preciso retomá-las para contra-argumentar, para mostrar às vezes o contrário do que dizem. Não é dizer "ah, parabéns", ou para se divertir. É para trabalhar, é um ponto de partida, não de chegada.

Revista Veras: Seria aproveitar-se do caso, por exemplo, de um aluno ter gostado de um determinado site e outro não, e do debate sobre isso aflorar uma interpretação sobre a confiabilidade e a pertinência daquelas informações?

Flora Perelman: Sim. Em nossas pesquisas gravamos as aulas e os argumentos chegam a níveis impensáveis. Por exemplo, sobre o tema da verdade. Para os alunos esse é um tema-chave. 0 problema é que, para eles, a verdade é igual à realidade. $\mathrm{E}$, no entanto, o que precisa- 
mos fazer aqui é mostrar-lhes que a verdade é impossível. Mas como se chega a isso? É um conceito filosófico esse de mostrar que cada fato que acontece no mundo é interpretado. É inevitável a interpretação, sempre. E é preciso trabalhar muito para começar a descobrir isso porque a ideia mais direta é que a verdade é o oposto da mentira. Geralmente o pensamento do aluno é dicotômico: verdade e mentira, esquerda e direita. Esse pensamento dicotômico também está na sociedade, como os bons e os maus. Sempre há ideias absolutamente dicotômicas e fazê-los entrar na dialética é difícil.

Revista Veras: E o debate a Sra. entende que ajuda os alunos a entrarem nessa dialética, na diferença de opiniões?

Flora Perelman: Sim, é a única forma.

Revista Veras: E sobre a busca por imagens na internet, o que suas pesquisas revelaram?

Flora Perelman: 0 que temos observado nesses anos é que tanto alunos quanto professores não entram nos sites quando pesquisam imagens em um buscador. Vimos que os professores aceitavam sem discussão as imagens que os alunos escolhiam, como em um álbum de figurinhas. Não davam importância ao fato, por exemplo, de que se o tema era a imigração não bastava colocar ali a imagem de um barco velho. Não havia validação da fonte em relação às imagens, como uma fonte de estudos que também precisa ser validada.

Revista Veras: Há uma expressão que a Sra. usa que achei ótima sobre procura na internet: 'a chave são as palavras-chave'. Talvez também seja um tema negligenciado pelos professores, que pensem que as palavras de busca sejam óbvias, o que nem sempre é.

Flora Perelman: A busca pela palavra-chave cria um aprofundamento do conceito. Por isso que é uma chave. A chave está na construção das palavras-chave, e as discussões sobre os conceitos que se põem em jogo. Esse é um processo construtivo muito interessante de se fazer com os alunos. Vou dar um exemplo: em um momento estávamos na sala de aula com alunos do Ensino Fundamental, mas sem lousa digital. $E$ antes de irmos à sala de informática (porque naquela época não tínhamos computadores para cada aluno), demos um pedaço de papel por grupo. Estávamos estudando com os alunos o tema da escravidão e a entrada dos negros escravizados pelo Rio da Prata. E lhes propusemos que, em grupos, pensassem em quais palavras teriam 
que colocar no buscador para achar o que queriam saber. Gravamos a discussão. 0 que encontramos? Discutiam que não poderia ser "Argentina", mas "Rio da Prata". Se buscassem "Argentina" não sairia nada porque naquele momento não havia ainda a República Argentina, era o Vice-reinado. "Não ponha 'negros'; ponha 'negros escravos' porque havia negros que não eram escravos". "Mas se não pomos 'Rio da Prata' sairá também escravos de outros países". "0 Google não pensa", já havíamos trabalhado sobre isso, "quem tem que pensar é quem busca". As discussões passavam por diversas ações de interagir saberes sobre determinado conteúdo.

Revista Veras: Isso porque de acordo com a hierarquia das palavras-chave virá um resultado de pesquisa?

Flora Perelman: Eles descobriram que se pusessem apenas "negros" os resultados não estavam relacionados com o que buscavam. Se punham "negros escravos" também não chegavam a sites vinculados com o que estavam buscando, que é um tema específico. Se alguém não expressa claramente nas palavras-chave o que está buscando não encontrará o que procura. Mas isso foi um trabalho de muita análise, de que a chave está em quais informações eu dou ao buscador. Por isso eu digo que é preciso saber para buscar.

Revista Veras: No livro "Ensinando a ler na Internet" se defende a tese de que é preciso criar espaços de reflexão sobre a busca de informações na web. Como se cria esse espaço de reflexão na sala de aula?

Flora Perelman: De muitas maneiras. Uma que nos tem ajudado muito é colocar as palavras-chave em uma lousa digital e ver coletivamente os resultados com as crianças. Fizemos, por exemplo, um exercício de pesquisar a vida de [Hans Christian] Andersen. Colocamos 'Andersen' e apareceram biografias do escritor, mas também um site de motores, outro de uma escola, médicos com esse nome etc. Pedíamos que indicassem quais não serviam para a biografia. E perguntamos: "Por que apareceu tudo isso que não estávamos buscando?". Isso é importante porque a ideia que as crianças têm é que o navegador busca o que eu estou querendo encontrar. Há desenhos de crianças especulando como funcionaria o Google que mostram os especialistas, que haviam feito universidade, buscando as informações pedidas. "Mas que especialista é esse que quando eu peço Andersen me coloca uma fábrica de motores?!" Fazemos tudo isso para conceituar a ideia de que se eu não dou as chaves o buscador busca palavras, e Andersen também pode ser um médico, uma fábrica de motores, uma escola... Discutir isso com os alunos dá muito resultado porque as crianças se põem 
então a pensar sobre a palavra-chave. 0 uso que se faz dela refletirá o resultado, e isso é que permite tirar conclusões. "Se não há um especialista por trás, o que move essa pesquisa que faço?"

Revista Veras: Em um artigo sobre a escrita de textos argumentativos a Sra. comenta da dificuldade que é para uma criança a situação de prever um argumento contrário e contra-argumentar sem a presença explícita de um interlocutor. Daí os textos argumentativos tenderem a ser mais curtos. Como se supera essa dificuldade da ausência do interlocutor, falando agora na produção de textos?

Flora Perelman: Em relação à produção escrita é preciso fazer muito trabalho. Nós temos um tipo de escrita que tem pouca divulgação, que chamamos de 'escrita de trabalho'. Que não é a escrita final, nem um rascunho. São todos os textos que servem para o trabalho, mas que não têm uma ordem. É, por exemplo, pensar argumentos sem ordená-los, e trabalhar esses argumentos - esse é um conceito da língua escrita. A escrita, ao deixar marcas, permite reconstruir o conhecimento porque a escrita ajuda a transformar o que aquela pessoa produz. A escrita de trabalho intelectual tem essa função.

Revista Veras: Essa escrita de trabalho que a Sra. menciona seria, por exemplo, o planejamento de um texto?

Flora Perelman: São anotações, às vezes caóticas, aproximações ao texto, que depois vão ser avaliadas, "ah, vou começar por este argumento, que é mais forte". Ou vou começar com um que seja facilmente rebatido para chegar a um que o leitor não conseguirá encontrar um contra-argumento. Essa é uma decisão estratégica de argumentação, mas para chegar a essa lógica eu preciso ter feito muita "escrita de trabalho". Depois vem o planejamento, o desenho, é outra coisa. A escola nega a escrita de trabalho. Pensa-se apenas na escrita definitiva, ou no rascunho. Mas essa escrita caótica, liberta, a escola também precisa suportar. Essa é a base, é como o germe da escrita. 0 professor tem que tomar consciência que esta é uma ferramenta fundamental, não porque foi tema de classe mas porque ele a usa e não sabe que a usa. Mas disso não se fala, não se faz consciente. E pede-se ao aluno que escreva de forma linda, prolixa. Nesse sentido, a minha primeira investigação acadêmica [sobre os cadernos de classe dos alunos] me ajudou muito. 0 que fazemos nas capacitações é que o professor escreva com outros colegas. Por exemplo, entre três docentes há dois que são encarregados de escrever e um que registra tudo o que o grupo comenta. Depois vamos criando o caminho. E o professor vai pensando, e descobrindo: "ah, então é necessário..." 
Sim! Não se pode pensar num texto argumentativo sem essa "escrita de trabalho". E para fazer essa "escrita de trabalho", quem sabe, será preciso pensar também "ao contrário" porque esse é um trabalho estratégico. É preciso pensar no outro, já que é um texto aberto; mas como esse outro não está presente, tudo fica mais difícil. Eu preciso indagar como meu interlocutor poderia contra-argumentar o que estou dizendo para poder responder a isso.

Revista Veras: Que influência a linguagem usada nas mídias sociais, especialmente as abreviaturas tão comuns no Whatsapp, tem na escrita formal dos alunos em seu período de alfabetização?

Flora Perelman: Essa é uma função da escola: refletir sobre a linguagem não diz respeito somente a substantivos, adjetivos e verbos. Diz respeito também à diversidade de usos de acordo com o contexto. Eu não falo igual com meu amigo e com o professor, ou com alguém que veio de outro país. É preciso adequar a linguagem ao contexto e isso também vale para a língua escrita. 0 WhatsApp é uma linguagem escrita que quanto mais abreviada for, mais efetiva é. Então, é preciso refletir isso com os alunos: que cada meio e cada contexto usa uma linguagem diferente. Essa reflexão sobre a linguagem vai se passar tanto no oral quanto no escrito, e é um problema sério para o aluno distinguir como intercambiar sua linguagem. Isso se aprende na escola, não na rua.

Revista Veras: Mas a escola finge não existir o Whatsapp...

Flora Perelman: Claro, e que um tipo de linguagem seria legítima enquanto outro perderia consistência, 'não se pode escrever assim...'.

Revista Veras: Por que a Sra. defende a prática de escrever hipertextos de forma coletiva?

Flora Perelman: Primeiramente é preciso se criar um conhecimento bastante sintético, um painel sobre determinado tema. Vou dar um exemplo feito com um grupo de alunos entre dez e onze anos que estudavam a Revolução de Maio de 1810, que foi um passo rumo à independência argentina. Cada grupo ficou encarregado de pesquisar uma das causas daquele tema: um pegou a Revolução Francesa; outro a Revolução Industrial; outro as invasões inglesas, que são todas consideradas causas desse evento. 0 objetivo ao se trabalhar com hipertextos era mostrar que um fato histórico é multicausal, e que as causas que contribuíram para ele foram gestadas ao longo de muito 
tempo, e não aconteceram de um dia para outro. Cada grupo buscou informações específicas sobre cada uma dessas causas e trabalhamos coletivamente os vínculos, usando folhas de papel para mostrar a estrutura dos hipertextos, ou seja, que isto aqui está vinculado àquilo etc. Foi uma experiência fabulosa.

Revista Veras: Por que é importante para o professor saber quais são os sites mais navegados pelos alunos e a relação que eles têm com os meios digitais?

Flora Perelman: Primeiramente porque não podemos desconhecer. É um ponto de partida. Os sites que os alunos conhecem e frequentam é a matéria-prima do professor. Se não sei com que matéria-prima eu trabalho, faço isso às cegas. Estou ensinando algo que não sei como vai cair em cada um. E como vou avaliar, se não conheço o ponto de partida de cada aluno? 0 ponto de partida penso que é muito maior do que uma prova. Há um monte de saberes que preciso levar em conta, e que podem ser muito ricos na forma como vou criar as situações didáticas. "Quem vou colocar junto com quem?" Porque se há uma criança que é bem desenvolvida em termos de navegação é bom colocá-la junto com outra que não está tão avançada nesse processo, para que possa aprender com seu colega. Se ponho todos juntos, ou separo os que sabem mais daqueles que sabem menos, não há circulação de saberes. É preciso pensar sobre essas trajetórias de conhecimento. Há, por exemplo, crianças que são fanáticas por dinossauros; outras são especialistas em futebol, e por isso sabem muito sobre os países; há crianças que não gostam de literatura, mas gostam de outros tipos de conhecimento. E não aproveitamos toda essa investigação feita por esses especialistas. Então, para mim essa é uma ferramenta básica para se pensar didaticamente o que fazer com isso.

Revista Veras: A distância entre o conhecimento digital de professores e alunos tende a se tornar nula na medida em que as novas gerações de professores 'nativos digitais' assumam seus lugares. 0 que acontecerá então?

Flora Perelman: Há um problema aqui: é que os meios digitais trazem novos conteúdos de ensino. Antes não se ensinava a busca por informação. 0 professor pegava o livro e dizia aos alunos: "Estudem da página 4 à página 5 ". Não aprendíamos a buscar informação porque havia um livro didático que comprávamos e estudávamos por ali. 0 meio digital traz esse problema da busca, e é um problema enorme porque trouxe com ele uma biblioteca imensa! 0 professor, mesmo que seja um nativo digital, o que precisa ter claro é que ele tem um 
novo objeto de ensino que antes não havia, e que precisa estar no currículo. Por isso eu digo que os professores das novas gerações serem nativos digitais não soluciona essa questão.

Revista Veras: Ou seja, a função do professor continua sendo tão importante quanto antes...

Flora Perelman: Não, ela fica ainda mais importante porque se está diante de um meio absolutamente perigoso, que tem muitos endereços que não são escolares. Esse é um tema que não competia antes ao docente, mas agora se tornou outro objeto de ensino, é parte do trabalho de se ensinar a estudar. Isso foi delegado mais às famílias. É algo bastante recente esse caminho de se ensinar a estudar.

Revista Veras: E o livro, em meio a essa invasão digital, como fica? Qual a impressão que a Sra. tem em relação à leitura na escola?

Flora Perelman: Há um fenômeno muito interessante atualmente que são os booktubers. As editoras estão percebendo que estão vendendo mais livros aos jovens e crianças do que aos adultos, graças ao fenômeno dos booktubers no mundo inteiro. Por exemplo, na Feira de Livros da Argentina quando chega um deles, o levantam como se fosse Maradona, aplaudem, porque são ídolos. Isso não é maravilhoso? 0 mundo digital levar ao papel? Para quem nasceu digital, o livro de papel é uma descoberta. 